\title{
Next endoscopic approach for acute lower gastrointestinal bleeding without an identified source on colonoscopy: upper or capsule endoscopy?
}

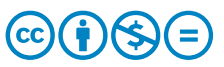

\author{
Authors \\ Naomi Uemura ${ }^{4}$, Kazuhiko Koike ${ }^{1}$ \\ Institutions \\ 1 Department of Gastroenterology, Graduate School of \\ Medicine, The University of Tokyo, 7-3-1 Hongo, \\ Bunkyo, Tokyo 113-8655, Japan \\ 2 Department of Gastroenterology and Hepatology, \\ National Center for Global Health and Medicine, 1-21-1 \\ Toyama, Shinjuku, Tokyo 162-8655, Japan \\ 3 Ohta Nishinouchi Hospital, 2-5-20 Nishinouchi, \\ Koriyama, Fukushima 963-8022, Japan \\ 4 Department of Gastroenterology and Hepatology, \\ National Center for Global Health and Medicine, \\ Kohnodai Hospital, 1-7-1 Kohnodai, Ichikawa City, Chiba \\ 272-8516, Japan
}

Tomonori Aoki ${ }^{1}$, Naoyoshi Nagata², Atsuo Yamada ${ }^{1}$, Takuro Shimbo ${ }^{3}$, Yuuki Matsushita², Akira Shimomura², Sakurako Kobayashi², Shiori Moriyasu², Ryota Niikura', Toshiyuki Sakurai², Yoshihiro Hirata', Junichi Akiyama²,

submitted 16.5.2018

accepted after revision 26.10.2018

Bibliography

DOI https://doi.org/10.1055/a-0824-6647 |

Endoscopy International Open 2019; 07: E337-E346

(c) Georg Thieme Verlag KG Stuttgart · New York

ISSN 2364-3722

Corresponding author

Naoyoshi Nagata, MD PhD, Department of

Gastroenterology and Hepatology, National Center for

Global Health and Medicine, 1-21-1 Toyama, Shinjuku,

Tokyo 162-8655, Japan

Fax: +81-3-32071038

nnagata_ncgm@yahoo.co.jp

\section{ABSTRACT}

Background and study aims We evaluated the utility of esophagogastroduodenoscopy (EGD) or capsule endoscopy (CE) as the next diagnostic approach after negative colonoscopy (CS) results in acute-onset hematochezia.

Patients and methods We retrospectively analyzed 401 patients emergently hospitalized for acute hematochezia who underwent CS within 48 hours of arriving at two large emergency hospitals and in whom a definitive bleeding source was not identified. The positive endoscopic findings, requirement for additional therapeutic procedures, and 30day rebleeding rates were compared among three strategies: EGD following CS (CS-EGD), CE following CS (CS-CE), and $C S$ alone. Predictors of positive endoscopic findings in the CS-EGD strategy were determined.

Results The rates of positive endoscopic findings and requirement for additional therapeutic procedures were $22 \%$ and $16 \%$, respectively, in CS-EGD and $50 \%$ and $28 \%$ in CSCE. The 30-day rebleeding rate did not significantly decrease in CS-EGD (8\%) or CS-CE (11\%) compared with CS alone (12\%). The rate of additional endoscopic therapies was lower in patients with a colonic diverticulum than in those without (CS-EGD: $3 \%$ vs. $33 \%, P=0.007$; CS-CE: $11 \%$ vs. $44 \%, P=0.147)$. A history of syncope, low blood pressure, blood urea nitrogen/creatinine ratio of $\geq 30$, and low albumin level significantly predicted EGD findings after negative $C S$ results $(P<0.05)$.

Conclusions When the definitive bleeding source is not identified by colonoscopy in patients with acute hematochezia, adjunctive endoscopy helps to identify the etiology and enables subsequent therapy, especially for patients without a colonic diverticulum. Upper gastrointestinal endoscopy is indicated for severe bleeding; other patients may be candidates for capsule endoscopy.

\section{Introduction}

Endoscopy is an essential tool for definitively diagnosing the etiology of acute gastrointestinal bleeding [1,2]. Previous studies have shown that, although the definitive bleeding source is detected by esophagogastroduodenoscopy (EGD) in $77 \%$ of patients with upper gastrointestinal bleeding (UGIB) [3], only $33 \%$ to $47 \%$ of patients with lower gastrointestinal bleeding (LGIB) receive a definitive diagnosis by colonoscopy (CS) despite full 
bowel preparation [4, 5]. In particular, among patients with colonic diverticular bleeding, a major cause of LGIB [6], both Western and Eastern studies have shown that less than one-third of patients receive a definitive diagnosis [7-12]. To date, little data are available on the next diagnostic approach for patients with acute hematochezia without an identified source on CS, and no clear guideline with regard to the optimal strategy has been established $[2,13]$. With this background, we considered whether additional endoscopy should be performed in such cases and, if so, whether EGD or capsule endoscopy (CE) should be chosen because UGIB or middle gastrointestinal bleeding (MGIB) may also cause massive hematochezia [5, 14]. Additional endoscopy after CS might identify the etiology of the gastrointestinal bleeding or decrease the incidence of rebleeding.

Therefore, to determine the utility of the next endoscopic approach for patients with hematochezia whose bleeding source was not definitively identified by CS, we evaluated the rates of positive endoscopic findings, requirement for additional therapeutic procedures, and 30-day rebleeding among three groups: patients who underwent CS alone (CS group), EGD following CS (CS-EGD group), and CE following CS (CS-CE group). We also analyzed these outcomes in subgroups of patients with or without a colonic diverticulum.

\section{Patients and methods}

\section{Study design, setting, and patients}

The study design was approved by the ethics committee of The University of Tokyo (Approval No.11528) and the institutional review board at the National Center for Global Health and Medicine (Approval No. 2163). This study was a retrospective observational study, carried out by the opt-out method of our hospital web site. We retrospectively identified patients who were admitted to the University of Tokyo Hospital or the National Center for Global Health and Medicine for acute-onset hematochezia from January 2009 to August 2016. We collected data from the patients' medical records in the endoscopic database and admission databases $[15,16]$. The endoscopic database is a searchable collection of records into which data are prospectively input after the use of endoscopic procedures by endoscopists. We searched the endoscopic database using the keywords "bleed," "blood," or "hematochezia" as indications for CS and selected patients who were assessed by CS ( We subsequently reviewed the endoscopic and clinical findings of all of these patients at the onset of bleeding using the electronic medical record system. The search identified consecutive patients with acute-onset hematochezia assessed by CS during their hospital stay. We then excluded patients in whom (i) CS was performed after 48 hours of bleeding, (ii) EGD was performed before CS, and (iii) CS revealed the definitive source of bleeding. We excluded patients assessed by elective CS because elective CS reportedly has a low detection rate of the definitive bleeding source [4]. In addition, by excluding patients who underwent EGD before CS, we selected patients whose clinical presentation before any endoscopic procedure was highly suggestive of LGIB. A definitive source detected by CS included lesions with active bleeding, a visible vessel or an adher-
This study was conducted at two large emergency hospitals.

(The University of Tokyo Hospital and the National Center for Global Health and Medicine)<smiles>C1=CC=C1</smiles>

1) Search of endoscopic database using keywords "bleed," "blood," or "hematochezia" among indications for CS

2) Using the electronic medical record system, patients who underwent CS during admission were identified, and the endoscopic and clinical findings of those patients were reviewed.<smiles>CCCC</smiles>

Acute-onset hematochezia assessed by CS during hospital stay $(n=1,511)$

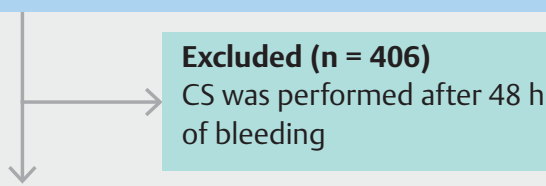

Acute-onset hematochezia assessed by CS within $48 \mathrm{~h}$ of onset (early CS) $(n=1,105)$

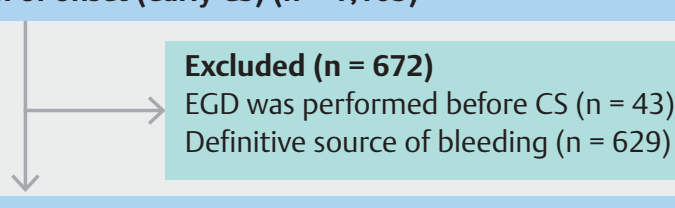

Acute-onset hematochezia whose definitive bleeding source was not identified by early CS as the first endoscopy $(n=433)$

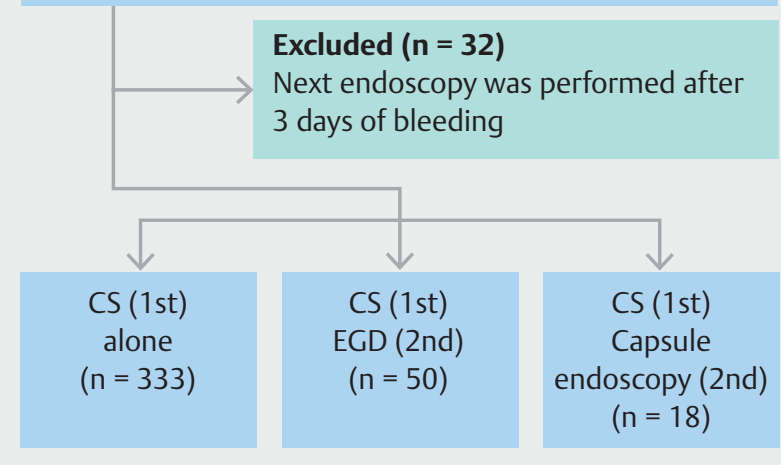

Outcomes

1. Positive findings of next endoscopy after CS

2. Need for therapeutic procedures

3. Thirty-day rebleeding

- Fig. 1 Flow chart for patient selection. CS, colonoscopy; EGD, esophagogastroduodenoscopy.

ent clot, and lesions such as friable tumors, colitis, and discrete ulcers [8]. This left patients in whom the definitive bleeding source was not identified by early CS as the first endoscopic procedure. Next, we excluded patients who underwent an addi- 
tional endoscopic procedure (EGD or CE) after 3 days of bleeding. Finally, we classified eligible patients into the following three groups: those who underwent CS alone as the only endoscopic procedure (CS alone group), those who underwent early EGD as the next endoscopic procedure after CS (CS-EGD group), and those who underwent early CE as the next endoscopic procedure after CS (CS-CE group).

\section{Next endoscopic procedure after CS}

Early CE performed within 3 days of admission reportedly has a higher diagnostic yield than CE performed 4 days or later after admission [17]. Therefore, the next endoscopic procedure after CS was defined as EGD or CE performed within 3 days of bleeding. Each next endoscopic procedure was performed in the same way between the two institutions. We used high-resolution electronic video endoscopes (GIF-H260, GIF-Q260J, or GIF-H260Z; Olympus Optical, Tokyo, Japan) or the Pillcam SB, SB2, or SB3 CE device (Given Imaging, Yoqneam, Israel). Before $\mathrm{CE}$, patients were required to fast for 12 hours and take $40 \mathrm{mg}$ of simethicone orally to prevent gas bubble formation [18]. When the capsule reached the colon or at 8 hours after ingestion (by which time the battery would presumably have run out), the recording device and sensor array were removed. Experienced gastroenterologists with more than 5 years of CE experience (S.T. and Y.A.), who had the patients' clinical background information, reviewed the CE images. All management decisions were made at the discretion of the attending physician.

\section{Outcome criteria}

The outcomes of interest were extracolonic positive findings on the next endoscopic procedure after $\mathrm{CS}$, need for additional therapeutic procedures, and 30 -day rebleeding rate.

Positive endoscopic findings included a bleeding source (angioectasia requiring intervention, tumor, ulcer, varix, and Meckel's diverticulum) and blood without a lesion $[3,19]$. When blood without a lesion was detected on the next endoscopic procedure, additional examinations such as double-balloon endoscopy (DBE) or Meckel's diverticulum scintigraphy were performed to identify a definitive bleeding source.

Therapeutic procedures included endoscopy, interventional radiology, or surgery. Endoscopic intervention was the first-line treatment when stigmata of recent hemorrhage were detected on EGD or DBE. Interventional radiology or surgery was performed in patients with a tumor, Meckel's diverticulum, or massive bleeding that did not resolve with endoscopic treatment.

Thirty-day rebleeding was defined as overt bleeding within 30 days after hemostasis accompanied by blood transfusion and/or a further $\geq 20 \%$ decrease in the hematocrit [14].

\section{Statistical analysis}

To simplify the clinical application, all continuous data were categorized using either statistical break points or standard clinical cutoff points. The characteristics and outcomes of the CS alone group, CS-EGD group, and CS-CE group were compared using a univariate analysis with Pearson's chi-squared test or Fisher's exact test as appropriate. We evaluated comorbidities with reference to the Charlson comorbidity index [20]. Predictive factors for positive endoscopic findings were evaluated by univariate analysis using Pearson's chi-squared test or Fisher's exact test as appropriate. Individual odds ratios and $95 \%$ confidence intervals were computed for each variable using logistic regression analysis or exact logistic regression analysis as appropriate.

A $P$ value of $<0.05$ was considered statistically significant. All data were statistically analyzed using STATA version 13 software (StataCorp, College Station, TX, United States).

\section{Results}

\section{Patient characteristics}

In total, 401 patients with acute-onset hematochezia whose definitive bleeding source was not identified by early CS as the first endoscopic procedure were evaluated in this study. Among these patients, 274 (68.3\%) were male, and the mean age of the study group was 69.8 years. The CS alone group comprised 333 patients, the CS-EGD group comprised 50 patients, and the CS-CE group comprised 18 patients ( $\mathbf{F i g . 1} \mathbf{1}$ ).

The patient characteristics in each group are shown in $>$ Table 1. Compared with the CS alone group, both the CS-EGD and CS-CE groups had significantly higher rates of low blood pressure, low hemoglobin level, low albumin level, and the need for transfusion during the first 24 hours, the presence of blood in the colon and terminal ileum on CS, significantly lower rates of a body mass index of $\geq 25 \mathrm{~kg} / \mathrm{m}^{2}$, and the presence of a colonic diverticulum. The CS-EGD group had a significantly higher rate of non-aspirin antiplatelet drug use than the CS-CE group. However, these two groups were similar with respect to age, sex, presenting symptoms, initial vital signs, laboratory data, comorbidities, blood transfusion during the first 24 hours, presence of a colonic diverticulum, presence of blood in the colon or terminal ileum on CS, and most medication-related variables.

\section{Positive endoscopic findings and need for additional therapeutic procedures \\ CS-EGD group}

The rate of positive endoscopic findings in the CS-EGD group was $22 \%$ ( $\mathbf{F i g . 2 a ) , ~ i n c l u d i n g ~ p e p t i c ~ u l c e r s ~ ( ~} 8 \%$ ), cancer (4\%), and angioectasia (2\%) in the stomach and peptic ulcers (6\%) and cancer $(2 \%)$ in the duodenum ( $\triangleright$ Table 2 ). The rate of therapeutic procedures was $16 \%$, including endoscopic intervention (14\%) and interventional radiology (2\%). No patients underwent surgical intervention.

\section{CS-CE group}

The rate of positive endoscopic findings in the CS-CE group was $50 \%$ ( $\$$ Fig. $2 a$ ), including ulcers (16\%), angioectasia (6\%), and blood without a definitive bleeding source $(28 \%)$ in the small bowel ( $\triangleright$ Table 2). Additional CE also detected blood in the colon without a bleeding source (28\%) and found no bleeding source in the stomach or duodenum. The rate of therapeutic procedures was $28 \%$, including endoscopic (11\%) and surgical 
Dable 1 Patient characteristics $(n=401)$.

\begin{tabular}{|c|c|c|c|c|c|c|}
\hline \multirow[t]{2}{*}{ Characteristics } & \multirow{2}{*}{$\begin{array}{l}\text { CS alone } \\
\text { group }(n=333)\end{array}$} & \multirow{2}{*}{$\begin{array}{l}\text { CS-EGD } \\
\text { group }(n=50)\end{array}$} & \multirow{2}{*}{$\begin{array}{l}\text { CS-CE group } \\
(n=18)\end{array}$} & \multicolumn{3}{|l|}{$P$ value } \\
\hline & & & & $\begin{array}{l}\text { (CS alone } \\
\text { vs. CS-EGD) }\end{array}$ & $\begin{array}{l}\text { (CS alone } \\
\text { vs. CS-CE) }\end{array}$ & $\begin{array}{l}\text { (CS-EGD } \\
\text { vs. CS-CE) }\end{array}$ \\
\hline Age $\geq 65 y$ & $236(70.9)$ & $27(54.0)$ & $9(50.0)$ & 0.016 & 0.060 & 0.771 \\
\hline Male sex & $226(67.9)$ & $34(68.0)$ & $14(77.8)$ & 0.985 & 0.447 & 0.435 \\
\hline $\mathrm{BMI} \geq 25 \mathrm{~kg} / \mathrm{m}^{21}$ & $99(29.7)$ & $7(14.0)$ & $1(5.6)$ & 0.020 & $0.030^{7}$ & $0.671^{2}$ \\
\hline Current drinker & $147(44.1)$ & $23(46.0)$ & 7 (38.9) & 0.805 & 0.662 & 0.602 \\
\hline Current smoker & $54(16.5)$ & $5(10.6)$ & $0(0.0)$ & $0.394^{7}$ & $0.088^{7}$ & $0.311^{7}$ \\
\hline Syncope ${ }^{3}$ & $38(11.4)$ & $7(14.0)$ & $4(22.2)$ & 0.596 & $0.250^{7}$ & $0.464^{7}$ \\
\hline Diarrhea & $12(3.6)$ & $4(8.0)$ & $0(0.0)$ & $0.142^{7}$ & $1.000^{7}$ & $0.567^{7}$ \\
\hline Abdominal tenderness & $24(7.2)$ & $3(6.0)$ & $1(5.6)$ & $1.000^{7}$ & $1.000^{7}$ & $0.945^{7}$ \\
\hline NSAIDs & $41(12.3)$ & $7(14.0)$ & $4(22.2)$ & 0.737 & $0.266^{7}$ & $0.464^{7}$ \\
\hline Low-dose aspirin ${ }^{4}$ & $96(28.8)$ & $12(24.0)$ & $5(27.8)$ & 0.479 & $1.000^{7}$ & 0.758 \\
\hline Non-aspirin antiplatelet drugs ${ }^{5}$ & $71(21.3)$ & $11(22.0)$ & $0(0.0)$ & 0.913 & $0.030^{7}$ & $0.030^{7}$ \\
\hline Anticoagulants ${ }^{6}$ & $34(10.2)$ & $8(16.0)$ & $4(22.2)$ & 0.222 & $0.117^{7}$ & $0.719^{7}$ \\
\hline Acetaminophen & $7(2.1)$ & $1(2.0)$ & $0(0.0)$ & $1.000^{7}$ & $1.000^{7}$ & $1.000^{7}$ \\
\hline Corticosteroid & $13(3.9)$ & $7(14.0)$ & $0(0.0)$ & 0.003 & $1.000^{7}$ & $0.177^{7}$ \\
\hline Proton pump inhibitor & $121(36.3)$ & $17(34.0)$ & $5(27.8)$ & 0.748 & $0.616^{7}$ & 0.772 \\
\hline Heart rate $\geq 100 / \mathrm{min}$ & $62(18.6)$ & $12(24.0)$ & $5(27.8)$ & 0.369 & $0.355^{7}$ & $0.758^{7}$ \\
\hline Systolic blood pressure $\leq 100 \mathrm{mmHg}$ & $48(14.4)$ & $15(30.0)$ & $8(44.4)$ & 0.006 & 0.001 & 0.267 \\
\hline Hemoglobin $<8.0 \mathrm{~g} / \mathrm{L}$ & $34(10.2)$ & $20(40.0)$ & $11(61.1)$ & $<0.001$ & $<0.001$ & 0.123 \\
\hline Platelet count $\leq 150 \times 10^{3} / \mathrm{mL}$ & $45(13.5)$ & $12(24.0)$ & $4(22.2)$ & 0.052 & $0.295^{7}$ & $1.000^{7}$ \\
\hline PT-INR $\geq 1.5$ & $26(7.8)$ & $7(14.0)$ & $4(22.2)$ & 0.146 & $0.057^{7}$ & $0.464^{7}$ \\
\hline BUN $/ \mathrm{Cr}$ ratio $\geq 30$ & $61(18.3)$ & $13(26.0)$ & $2(11.1)$ & 0.200 & $0.751^{7}$ & $0.321^{7}$ \\
\hline Albumin $<3.0 \mathrm{~g} / \mathrm{dL}$ & $42(12.6)$ & $16(32.0)$ & $7(38.9)$ & $<0.001$ & 0.002 & 0.596 \\
\hline Diabetes mellitus & $79(23.7)$ & $12(24.0)$ & $2(11.1)$ & 0.966 & $0.265^{7}$ & $0.323^{7}$ \\
\hline Cerebrovascular disease & $42(12.6)$ & $8(16.0)$ & $1(5.6)$ & 0.507 & $0.710^{7}$ & $0.427^{7}$ \\
\hline Chronic pulmonary disease & $14(4.2)$ & $1(2.0)$ & $0(0.0)$ & $0.704^{7}$ & $1.000^{7}$ & $1.000^{7}$ \\
\hline Dementia & $20(6.0)$ & $3(6.0)$ & $0(0.0)$ & $1.000^{7}$ & $0.612^{7}$ & $0.560^{7}$ \\
\hline Connective tissue disease & $11(3.3)$ & $3(6.0)$ & $0(0.0)$ & $0.407^{7}$ & $1.000^{7}$ & $1.000^{7}$ \\
\hline Myocardial infarction & $80(24.0)$ & $10(20.0)$ & $2(11.1)$ & 0.531 & $0.264^{7}$ & $0.494^{7}$ \\
\hline Congestive heart failure & $18(5.4)$ & $1(2.0)$ & $0(0.0)$ & $0.489^{7}$ & $0.612^{7}$ & $1.000^{7}$ \\
\hline Ulcer disease & $34(10.2)$ & $5(10.0)$ & $4(22.2)$ & $1.000^{7}$ & $0.117^{7}$ & $0.231^{7}$ \\
\hline Chronic kidney disease & $83(24.9)$ & $16(32.0)$ & $5(27.8)$ & 0.287 & $0.783^{7}$ & $1.000^{7}$ \\
\hline Peripheral vascular disease & $13(3.9)$ & $2(4.0)$ & $0(0.0)$ & $1.000^{7}$ & $1.000^{7}$ & $1.000^{7}$ \\
\hline AIDS & $0(0.0)$ & $0(0.0)$ & $0(0.0)$ & NA & NA & NA \\
\hline Liver cirrhosis & $11(3.3)$ & $8(16.0)$ & $3(16.7)$ & $<0.001$ & $0.029^{7}$ & $1.000^{7}$ \\
\hline Malignancy & $57(17.1)$ & $18(36.0)$ & $6(33.3)$ & 0.002 & 0.081 & 0.839 \\
\hline Blood transfusion during the first $24 \mathrm{~h}$ & $97(29.1)$ & $27(54.0)$ & $10(55.6)$ & $<0.001$ & 0.018 & 0.910 \\
\hline Colonic diverticulum on CS & 306 (91.9) & $29(58.0)$ & $9(50.0)$ & $<0.001$ & $<0.001$ & 0.558 \\
\hline
\end{tabular}


- Table 1 (Continuation)

\begin{tabular}{|c|c|c|c|c|c|c|}
\hline \multirow[t]{2}{*}{ Characteristics } & \multirow{2}{*}{$\begin{array}{l}\text { CS alone } \\
\text { group }(n=333)\end{array}$} & \multirow{2}{*}{$\begin{array}{l}\text { CS-EGD } \\
\text { group }(n=50)\end{array}$} & \multirow{2}{*}{$\begin{array}{l}\text { CS-CE group } \\
(n=18)\end{array}$} & \multicolumn{3}{|l|}{$P$ value } \\
\hline & & & & $\begin{array}{l}\text { (CS alone } \\
\text { vs. CS-EGD) }\end{array}$ & $\begin{array}{l}\text { (CS alone } \\
\text { vs. CS-CE) }\end{array}$ & $\begin{array}{l}\text { (CS-EGD } \\
\text { vs. CS-CE) }\end{array}$ \\
\hline Blood in the colon on CS & $69(20.7)$ & $20(40.0)$ & $11(61.1)$ & 0.003 & $<0.001$ & 0.123 \\
\hline Blood in the terminal ileum on $\mathrm{CS}^{7}$ & $9(3.4)$ & $14(34.2)$ & $8(44.4)$ & $<0.001$ & $<0.001$ & 0.451 \\
\hline
\end{tabular}

Data are presented as $\mathrm{n}(\%)$.

Abbreviations: CS, colonoscopy; EGD, esophagogastroduodenoscopy; CE, capsule endoscopy; BMI, body mass index; NSAIDs, nonsteroidal anti-inflammatory drugs; PT-INR, prothrombin time-international normalized ratio; BUN, blood urea nitrogen; $\mathrm{Cr}$, creatinine; AIDS, acquired immunodeficiency syndrome; NA, not available.

Medication use was defined as intermittent or regular oral administration within 2 weeks before admission. Comorbidities were evaluated with reference to the

Charlson comorbidity index [20].

${ }^{1}$ BMI was calculated as weight divided by height squared $\left(\mathrm{kg} / \mathrm{m}^{2}\right)$.

2 Syncope included a transient altered mental status defined as a Glasgow coma scale score of $\leq 14$ or a history of syncope.

${ }^{3}$ Low-dose aspirin included enteric-coated aspirin and buffered aspirin.

${ }^{4}$ Antiplatelet drugs (non-aspirin) included clopidogrel, ticlopidine, dipyridamole, cilostazol, sarpogrelate hydrochloride, ethyl icosapentate, dilazep hydrochloride,

limaprost alfadex, and beraprost.

${ }^{5}$ Anticoagulants included warfarin, dabigatran etexilate, rivaroxaban, apixaban, and edoxaban.

${ }^{6}$ Blood in the terminal ileum on CS was reviewed in 323 patients.

${ }^{7}$ Analyzed using Fisher's exact test.

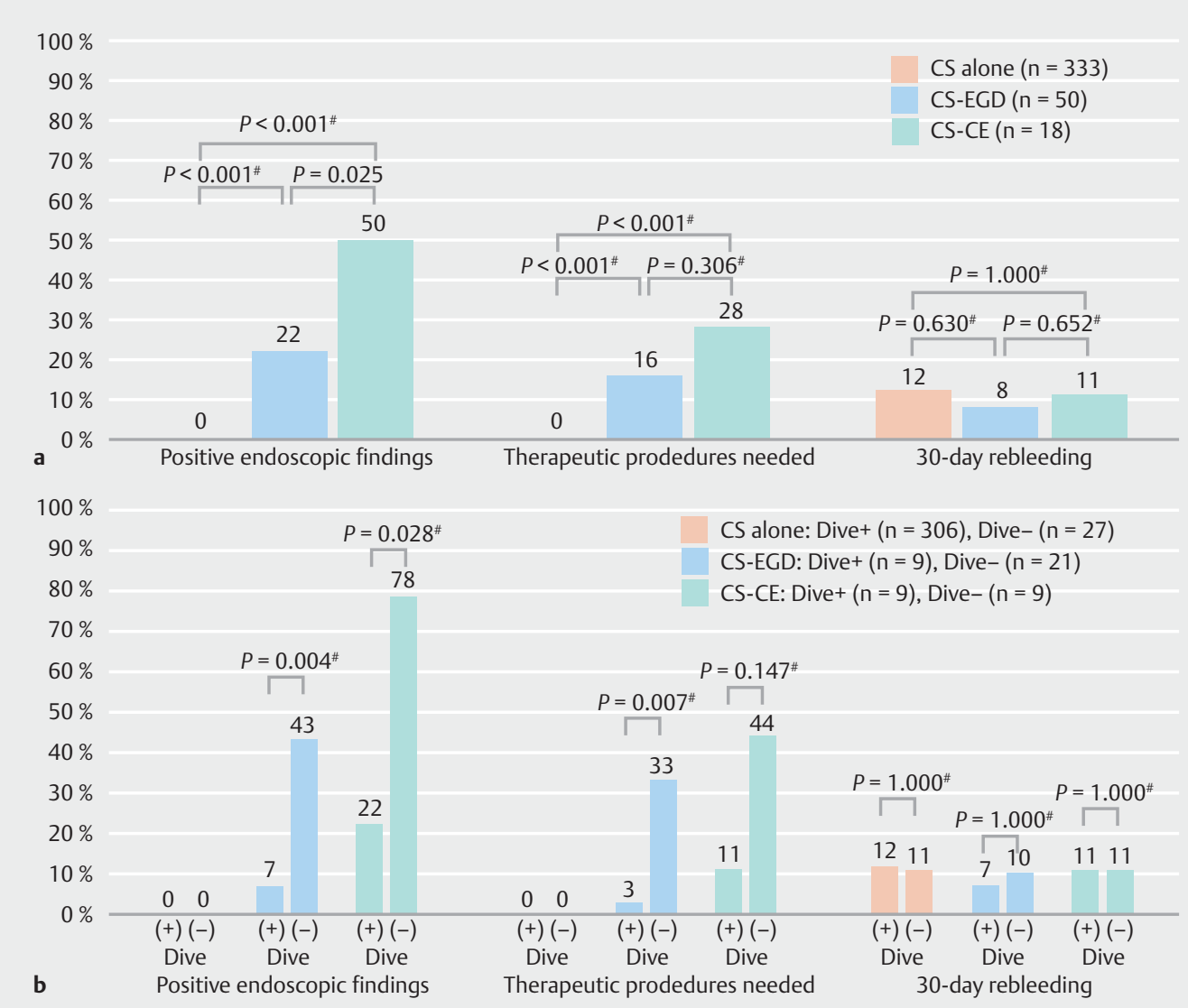

Fig. 2 Patient outcomes after negative CS results. a Rates of positive endoscopic findings, requirement for therapeutic procedures, and 30-day rebleeding in CS alone group, CS-EGD group, and CS-CE group. b Subgroup analysis of patients with and without a colonic diverticulum. \#Analyzed using Fisher's exact test. CS, colonoscopy; EGD, esophagogastroduodenoscopy; CE, capsule endoscopy; Dive, diverticulum. 
- Table 2 Positive findings of next endoscopic procedure after CS.

\begin{tabular}{|c|c|}
\hline Positive findings & n (\%) \\
\hline \multicolumn{2}{|l|}{ EGD findings in CS-EGD group $(n=50)$} \\
\hline Total & $11(22.0)$ \\
\hline \multicolumn{2}{|l|}{ - Stomach } \\
\hline - Peptic ulcer & $4(8.0)$ \\
\hline - Cancer & $2(4.0)$ \\
\hline - Angioectasia & $1(2.0)$ \\
\hline \multicolumn{2}{|l|}{ - Duodenum } \\
\hline - Peptic ulcer & $3(6.0)$ \\
\hline - Cancer & $1(2.0)$ \\
\hline \multicolumn{2}{|l|}{ CE findings in CS-CE group $(n=18)$} \\
\hline Total & $9(50.0)$ \\
\hline \multicolumn{2}{|l|}{ - Small bowel } \\
\hline - Ulcer & $3(16.6)$ \\
\hline - Angioectasia & $1(5.6)$ \\
\hline - Blood without bleeding source ${ }^{1}$ & $5(27.8)$ \\
\hline \multicolumn{2}{|c|}{$\begin{array}{l}\text { Abbreviations: CS, colonoscopy; EGD, esophagogastroduodenoscopy; CE, } \\
\text { capsule endoscopy. } \\
\text { 'After capsule endoscopy, double-balloon endoscopy ( } n=4) \text { or Meckel's di- } \\
\text { verticulum scintigraphy }(n=1) \text { were performed; the bleeding source diag- } \\
\text { noses were angioectasia in the small bowel }(n=1) \text {, Meckel's diverticulum } \\
(n=1) \text {, and unknown }(n=3) \text {. }\end{array}$} \\
\hline
\end{tabular}

(17\%) intervention. No patients underwent interventional radiology.

\section{CS-EGD group vs. CS-CE group}

The rate of positive endoscopic findings was significantly lower in the CS-EGD group (22\%) than in the CS-CE group (50\%) $(P=$ $0.025)$, and the rate of therapeutic procedures was not different $(16 \%$ vs. $28 \%, P=0.306)$ ( Fig. 2a).

\section{Subgroup analysis of patients with or without colonic diverticulum}

Patients without a colonic diverticulum had a significantly higher rate of positive endoscopic findings than those with a colonic

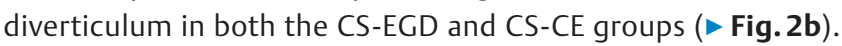
Patients without a colonic diverticulum had a higher rate of therapeutic procedures than those with a colonic diverticulum in both the CS-EGD and CS-CE groups, but this difference was not statistically significant in the CS-CE group ( $\vee$ Fig. 2 b).

\section{0-Day rebleeding rate}

The 30-day rebleeding rate did not decrease significantly in the CS-EGD group ( $8 \%$ ) or CS-CE group (11\%) compared with the CS alone group (12\%) ( $\triangleright$ Fig. $2 a$ ). In the subgroup analysis, the 30-day rebleeding rate was not significantly different between patients with a colonic diverticulum and those without among all three groups ( $\triangleright$ Fig. 2 b).

\section{Predictors of positive endoscopic findings}

Significant predictive factors for positive EGD findings in the CS-EGD group were a history of syncope, systolic blood pressure of $\leq 100 \mathrm{mmHg}$, blood urea nitrogen/creatinine (BUN/Cr) ratio of $\geq 30$, albumin of $<3.0 \mathrm{~g} / \mathrm{dL}$, no colonic diverticulum, and the presence of blood in the colon or the terminal ileum on CS ( $\triangleright$ Table 3 ). The only significant predictive factor for positive CE findings in the CS-CE group was the absence of a colonic diverticulum ( $>$ Table 3 ).

\section{Discussion}

The first question in the present study was whether we should perform an additional endoscopic procedure after obtaining negative $C S$ results. Bleeding sources identified by EGD included cancers, and more than one-quarter of patients in the CS-CE group required hemostatic interventions. Therefore, we considered that the additional endoscopic procedures were meaningful to some degree. Next, we considered for whom the additional endoscopic procedures should be performed. Based on our results, the absence of a colonic diverticulum on the initial CS was the indication for an additional endoscopic procedure because the rate of positive endoscopic findings was significantly higher in patients without than with a colonic diverticulum ( $\triangleright$ Supplementary Fig.1). Although we were often concerned about how to manage presumptive diverticular bleeding in clinical practice in the past, we now consider that observation without further endoscopy is acceptable in such patients because only $4 \%$ in the CS-EGD group and $11 \%$ in the CS-CE group required interventions.

The second question addressed in the present study was which endoscopic procedure would be preferred after negative CS results: EGD or CE? To date, investigation of small-bowel bleeding has been considered after EGD and CS [21]. In the present study, however, CE showed a higher rate of positive findings and the need for therapeutic procedures than did EGD, regardless of the fact that the patients' background factors were similar between the CS-EGD and CS-CE groups. Thus, we suggest a new strategy involving the use of CE before EGD ( $\triangleright$ Supplementary Fig. 1). A previous study revealed that, compared with other types of gastrointestinal bleeding (UGIB or LGIB), MGIB required a higher number of diagnostic procedures, more blood transfusions, and a longer hospital stay [22]. Based on our results, CE instead of EGD could lead to an early diagnosis and reduce these outcomes. Conversely, the predictors of positive EGD findings in our study were a history of syncope, systolic blood pressure of $\leq 100 \mathrm{mmHg}$, BUN/Cr ratio of $\geq 30$, and albumin of $<3.0 \mathrm{~g} / \mathrm{dL}$ that were similar to NOBLADS score [14] as the predictive score for severe bleeding and therapeutic procedures needed in the acute LGIB setting. These findings indicate that EGD may precede CE for patients with severe hematochezia ( $\triangleright$ Supplementary Fig. 1). When we applied this score to our CS-EGD group, the proportion of patients with a high score $(\geq 4)$ was higher in patients with positive EGD findings than in those with negative EGD findings ( $100 \%$ vs. $35 \%$, respectively; $P<0.001$ ) (data not shown). Thus, 
- Table 3 Predictors of positive EGD findings in CS-EGD group ( $n=50)$, and predictors of positive CE findings in CS-CE group ( $n=18)$.

\begin{tabular}{|c|c|c|c|c|c|c|c|c|}
\hline Characteristics & $\begin{array}{l}\text { Positive } \\
\text { EGD } \\
\text { findings } \\
(n=11)\end{array}$ & $\begin{array}{l}\text { Negative } \\
\text { EGD } \\
\text { results } \\
(n=39)\end{array}$ & $\begin{array}{l}\text { Crude OR } \\
(95 \% \mathrm{CI})\end{array}$ & $P$ value & $\begin{array}{l}\text { Positive } \\
\text { CE find- } \\
\text { ings } \\
(n=9)\end{array}$ & $\begin{array}{l}\text { Nega- } \\
\text { tive CE } \\
\text { results } \\
(n=9)\end{array}$ & $\begin{array}{l}\text { Crude OR } \\
(95 \% \mathrm{CI})\end{array}$ & $P$ value \\
\hline Age $\geq 65 y$ & $5(45.5)$ & $22(56.4)$ & $0.64(0.17-2.47)$ & $0.733^{1}$ & $5(55.6)$ & $4(44.4)$ & $1.56(0.24-10.0)$ & $1.000^{8}$ \\
\hline Male sex & $9(81.8)$ & $25(64.1)$ & $2.52(0.48-13.3)$ & 0.266 & $6(66.7)$ & $8(88.9)$ & $0.25(0.02-3.04)$ & $0.576^{8}$ \\
\hline $\mathrm{BMI} \geq 25 \mathrm{~kg} / \mathrm{m}^{22}$ & $2(18.2)$ & $5(12.8)$ & $1.51(0.25-9.11)$ & $0.641^{8}$ & $0(0.0)$ & $1(11.1)$ & $1(0-39)^{7}$ & $1.000^{8}$ \\
\hline Current drinker & $5(45.5)$ & $18(46.2)$ & $0.97(0.25-3.73)$ & $1.000^{8}$ & $4(44.4)$ & $3(33.3)$ & $1.6(0.24-10.8)$ & $1.000^{8}$ \\
\hline Current smoker & $2(20.0)$ & $3(8.1)$ & $2.83(0.40-19.9)$ & $0.285^{8}$ & $0(0.0)$ & $0(0.0)$ & NA & NA \\
\hline Syncope ${ }^{3}$ & $4(36.4)$ & $3(7.7)$ & $6.86(1.25-37.6)$ & $0.034^{8}$ & $2(22.2)$ & $2(22.2)$ & $1(0.11-9.23)$ & $1.000^{8}$ \\
\hline Diarrhea & $1(9.1)$ & $3(7.7)$ & $1.2(0.11-12.8)$ & $1.000^{8}$ & $0(0.0)$ & $0(0.0)$ & NA & NA \\
\hline $\begin{array}{l}\text { Abdominal } \\
\text { tenderness }\end{array}$ & $2(18.2)$ & $1(2.6)$ & $8.44(0.69-104)$ & $0.118^{8}$ & $1(11.1)$ & $0(0.0)$ & $1(0.03-\text { Infinity })^{\dagger \dagger}$ & $1.000^{8}$ \\
\hline NSAIDs & $2(18.2)$ & $5(12.8)$ & $1.51(0.25-9.11)$ & $0.641^{8}$ & $1(11.1)$ & $3(33.3)$ & $0.25(0.02-3.04)$ & $0.576^{8}$ \\
\hline Low-dose aspirin ${ }^{4}$ & $2(18.2)$ & $10(25.6)$ & $0.64(0.12-3.50)$ & $1.000^{8}$ & $2(22.2)$ & $3(33.3)$ & $0.57(0.07-4.64)$ & $1.000^{8}$ \\
\hline $\begin{array}{l}\text { Non-aspirin anti- } \\
\text { platelet drugs }{ }^{5}\end{array}$ & $2(18.2)$ & $9(23.1)$ & $0.74(0.13-4.07)$ & $1.000^{8}$ & $0(0.0)$ & $0(0.0)$ & NA & NA \\
\hline Anticoagulants ${ }^{6}$ & $1(9.1)$ & $7(18.0)$ & $0.46(0.05-4.18)$ & $0.666^{8}$ & $2(22.2)$ & $2(22.2)$ & $1(0.11-9.23)$ & $1.000^{8}$ \\
\hline Acetaminophen & $0(0.0)$ & $1(2.6)$ & $3.55(0-138)^{7}$ & $1.000^{8}$ & $0(0.0)$ & $0(0.0)$ & NA & NA \\
\hline Corticosteroid & $3(27.3)$ & $4(10.3)$ & $3.28(0.61-17.6)$ & $0.170^{8}$ & $0(0.0)$ & $0(0.0)$ & NA & NA \\
\hline $\begin{array}{l}\text { Proton pump } \\
\text { inhibitor }\end{array}$ & $5(45.5)$ & $12(30.8)$ & $1.88(0.48-7.36)$ & $0.475^{8}$ & $1(11.1)$ & $4(44.4)$ & $0.16(0.01-1.83)$ & $0.294^{8}$ \\
\hline $\begin{array}{l}\text { Heart rate } \\
\geq 100 / \text { min }\end{array}$ & $4(36.4)$ & $8(20.5)$ & $2.21(0.52-9.47)$ & $0.424^{8}$ & $3(33.3)$ & $2(22.2)$ & $1.75(0.22-14.2)$ & $1.000^{8}$ \\
\hline $\begin{array}{l}\text { Systolic blood pres- } \\
\text { sure } \leq 100 \mathrm{mmHg}\end{array}$ & $9(81.8)$ & $6(15.4)$ & $24.8(4.25-144)$ & $<0.001^{8}$ & $5(55.6)$ & $3(33.3)$ & $2.5(0.37-16.9)$ & $0.637^{8}$ \\
\hline $\begin{array}{l}\text { Hemoglobin } \\
<8.0 \mathrm{~g} / \mathrm{L}\end{array}$ & $7(63.6)$ & $13(33.3)$ & $3.5(0.87-14.2)$ & 0.090 & $6(66.7)$ & $5(55.6)$ & $1.6(0.24-10.8)$ & $1.000^{8}$ \\
\hline $\begin{array}{l}\text { Platelet count } \\
\leq 150 \times 10^{3} / \mu \mathrm{L}\end{array}$ & $3(27.3)$ & $9(23.1)$ & $1.25(0.27-5.72)$ & $1.000^{8}$ & $2(22.2)$ & $2(22.2)$ & $1(0.11-9.23)$ & $1.000^{8}$ \\
\hline PT-INR $\geq 1.5$ & $2(18.2)$ & $5(12.8)$ & $1.51(0.25-9.11)$ & $0.641^{8}$ & $2(22.2)$ & $2(22.2)$ & $1(0.11-9.23)$ & $1.000^{8}$ \\
\hline BUN $/ C r$ ratio $\geq 30$ & $7(63.6)$ & $6(15.4)$ & $9.63(2.14-43.4)$ & $0.003^{8}$ & $2(22.2)$ & $0(0.0)$ & $2.6(0.19-\operatorname{Infinity})^{7}$ & $0.471^{8}$ \\
\hline Albumin $<3.0 \mathrm{~g} / \mathrm{dL}$ & $9(81.8)$ & $7(18.0)$ & $20.6(3.62-117)$ & $<0.001$ & $4(44.4)$ & $3(33.3)$ & $1.6(0.24-10.8)$ & $1.000^{8}$ \\
\hline Diabetes mellitus & $2(18.2)$ & $10(25.6)$ & $0.64(0.12-3.50)$ & $1.000^{8}$ & $1(11.1)$ & $1(11.1)$ & $1(0.05-18.9)$ & $1.000^{8}$ \\
\hline $\begin{array}{l}\text { Cerebrovascular } \\
\text { disease }\end{array}$ & $2(18.2)$ & $6(15.4)$ & $1.22(0.21-7.12)$ & $1.000^{8}$ & $1(11.1)$ & $0(0.0)$ & $1(0.03-\text { Infinity })^{7}$ & $1.000^{8}$ \\
\hline $\begin{array}{l}\text { Chronic pulmonary } \\
\text { disease }\end{array}$ & $0(0.0)$ & $1(2.6)$ & $3.55(0-138)^{8}$ & $1.000^{8}$ & $0(0.0)$ & $0(0.0)$ & NA & NA \\
\hline Dementia & $1(9.1)$ & $2(5.1)$ & $1.85(0.15-22.5)$ & $0.534^{8}$ & $0(0.0)$ & $0(0.0)$ & NA & NA \\
\hline $\begin{array}{l}\text { Connective tissue } \\
\text { disease }\end{array}$ & $0(0.0)$ & $3(7.7)$ & $0.90(0-8.87)^{8}$ & $1.000^{8}$ & $0(0.0)$ & $0(0.0)$ & NA & NA \\
\hline $\begin{array}{l}\text { Myocardial } \\
\text { infarction }\end{array}$ & $2(18.2)$ & $8(20.5)$ & $0.86(0.15-4.80)$ & $1.000^{8}$ & $0(0.0)$ & $2(22.2)$ & $0.38(0-5.22)^{7}$ & $0.471^{8}$ \\
\hline $\begin{array}{l}\text { Congestive heart } \\
\text { failure }\end{array}$ & $0(0.0)$ & $1(2.6)$ & $3.55(0-138)^{8}$ & $1.000^{8}$ & $0(0.0)$ & $0(0.0)$ & NA & NA \\
\hline Ulcer disease & $3(27.3)$ & $2(5.1)$ & $6.94(0.99-48.5)$ & $0.064^{8}$ & $3(33.3)$ & $1(11.1)$ & $4(0.33-48.7)$ & $0.576^{8}$ \\
\hline
\end{tabular}


Table 3 (Continuation)

\begin{tabular}{|c|c|c|c|c|c|c|c|c|}
\hline Characteristics & $\begin{array}{l}\text { Positive } \\
\text { EGD } \\
\text { findings } \\
(n=11)\end{array}$ & $\begin{array}{l}\text { Negative } \\
\text { EGD } \\
\text { results } \\
(n=39)\end{array}$ & $\begin{array}{l}\text { Crude OR } \\
(95 \% \mathrm{Cl})\end{array}$ & $P$ value & $\begin{array}{l}\text { Positive } \\
\text { CE find- } \\
\text { ings } \\
(n=9)\end{array}$ & $\begin{array}{l}\text { Nega- } \\
\text { tive CE } \\
\text { results } \\
(n=9)\end{array}$ & $\begin{array}{l}\text { Crude OR } \\
(95 \% \mathrm{CI})\end{array}$ & $P$ value \\
\hline $\begin{array}{l}\text { Chronic kidney } \\
\text { disease }\end{array}$ & $4(36.4)$ & $12(30.8)$ & $1.29(0.32-5.24)$ & $0.728^{8}$ & $2(22.2)$ & $3(33.3)$ & $0.57(0.07-4.64)$ & $1.000^{8}$ \\
\hline $\begin{array}{l}\text { Peripheral vascular } \\
\text { disease }\end{array}$ & $1(9.1)$ & $1(2.6)$ & $3.8(0.22-66.2)$ & $0.395^{8}$ & $0(0.0)$ & $0(0.0)$ & NA & NA \\
\hline AIDS & $0(0.0)$ & $0(0.0)$ & NA & NA & $0(0.0)$ & $0(0.0)$ & NA & NA \\
\hline Liver cirrhosis & $4(36.4)$ & $4(10.3)$ & $5(1.00-24.9)$ & $0.059^{8}$ & $2(22.2)$ & $1(11.1)$ & $2.29(0.17-31.0)$ & $1.000^{8}$ \\
\hline Malignancy & $5(45.6)$ & $13(33.3)$ & $1.67(0.43-6.50)$ & $0.494^{8}$ & $4(44.4)$ & $2(22.2)$ & $2.8(0.36-21.7)$ & $0.620^{8}$ \\
\hline $\begin{array}{l}\text { Blood transfusion } \\
\text { during the first } 24 \mathrm{~h}\end{array}$ & $9(81.8)$ & $18(46.2)$ & $5.25(1.00-27.5)$ & $0.046^{8}$ & $5(55.6)$ & $5(55.6)$ & $1(0.16-6.42)$ & $1.000^{8}$ \\
\hline $\begin{array}{l}\text { Colonic diverticu- } \\
\text { lum on CS }\end{array}$ & $2(18.2)$ & $27(69.2)$ & $0.10(0.02-0.53)$ & $0.004^{8}$ & $2(22.2)$ & $7(77.8)$ & $0.08(0.01-0.75)$ & $0.028^{8}$ \\
\hline $\begin{array}{l}\text { Blood in the colon } \\
\text { on CS }\end{array}$ & $9(81.8)$ & $11(28.2)$ & $11.5(2.13-61.7)$ & $0.004^{8}$ & $6(66.7)$ & $5(55.6)$ & $1.6(0.24-10.8)$ & $1.000^{8}$ \\
\hline $\begin{array}{l}\text { Blood in the term- } \\
\text { inal ileum on } \mathrm{CS}^{8}\end{array}$ & $5(71.4)$ & $9(26.5)$ & $6.94(1.14-42.4)$ & $0.035^{8}$ & $5(55.6)$ & $3(33.3)$ & $2.5(0.37-16.9)$ & $0.637^{8}$ \\
\hline $\begin{array}{l}\text { Data regarding charact } \\
\text { Abbreviations: CS, col } \\
\text { confidence interval; PT } \\
\text { drome; NA, not availab } \\
\text { Medication use was def } \\
\text { Charlson comorbidity in } \\
{ }^{1} \text { Analyzed using Fisher } \\
{ }^{2} \text { BMI was calculated as } \\
{ }^{3} \text { Syncope included a tr } \\
{ }^{4} \text { Low-dose aspirin inclu } \\
{ }^{5} \text { Antiplatelet drugs (no } \\
\text { limaprost alfadex, anc } \\
{ }^{6} \text { Anticoagulants includ } \\
{ }^{7} \text { Analyzed using exact } \\
{ }^{8} \text { Blood in the terminal }\end{array}$ & $\begin{array}{l}\text { ristics are pre } \\
\text { noscopy; EGD } \\
\text { NR, prothrom } \\
\text { hed as interm } \\
\text { dex [20]. } \\
\text { exact test. } \\
\text { veight dividec } \\
\text { nsient altered } \\
\text { led enteric-co } \\
\text {-aspirin) incl } \\
\text { beraprost. } \\
\text { d warfarin, da } \\
\text { gistic regres } \\
\text { eum on CS wc }\end{array}$ & $\begin{array}{l}\text { height squar } \\
\text { ntal status de } \\
\mathrm{d} \text { aspirin and } \\
\mathrm{d} \text { clopidogrel, } \\
\text { atran etexilat } \\
\text { analysis. } \\
\text { eviewed in } 41\end{array}$ & $\begin{array}{l}\left(\mathrm{kg} / \mathrm{m}^{2}\right) . \\
\text { ed as a Glasgow coma s } \\
\text { ffered aspirin. } \\
\text { lopidine, dipyridamole, } \\
\text { rivaroxaban, apixaban, ar } \\
\text { tients in CS-EGD group. }\end{array}$ & $\begin{array}{l}\text { le score of } \leq \\
\text { ostazol, sarp } \\
\text { edoxaban. }\end{array}$ & $\begin{array}{l}\text { AIDs, nonste } \\
\text { ogen; } \mathrm{Cr} \text {, cre } \\
\text { mission. We }\end{array}$ & $\begin{array}{l}\text { lanti-infla } \\
\text { ine; AIDS, } \\
\text { luated com }\end{array}$ & $\begin{array}{l}\text { natory drugs; OR, odd } \\
\text { quired immunodeficier } \\
\text { pidities with reference }\end{array}$ & $\begin{array}{l}\text { io; Cl, } \\
\text { yn- } \\
\text { he } \\
\text { loride, }\end{array}$ \\
\hline
\end{tabular}

stratification of patients according to the NOBLADS score in the emergency room might be applicable to determining the indication for EGD as well as for triage to intensive care.

Because of the retrospective study design, decisions to perform additional endoscopic procedures were made at the discretion of the attending physician; this introduced selection bias into each group. For example, the decision of whether to perform additional endoscopy was influenced by colonoscopic findings. However, the rates of colonoscopic findings were not significantly different between CS-EGD and CS-CE groups, so may not have influenced the choice of EGD or CE as the additional endoscopy. Additionally, the small number of patients in the CS-CE group might result in an underpowered statistical analysis of positive CE finding predictors. Because the number of clinical outcomes (positive endoscopic findings) was less than 11 in our study, allowing us to include at most one predictive variable in multivariate analysis, a stratification model for selecting additional endoscopy could not be developed. Further prospective studies in multiple centers are needed to investigate this issue.
In conclusion, when CS did not identify the definitive bleeding source in patients with acute-onset hematochezia, additional endoscopy contributed to the identification of a new etiology and thus enabled subsequent therapy, especially for patients without a colonic diverticulum. CE might be the next endoscopic procedure after CS, whereas EGD should be performed before CE for patients with severe bleeding. These endoscopic techniques can lead to an improvement in performance of therapeutic procedures, but they do not appear to decrease the 30-day rebleeding rate.

\section{Acknowledgments}

We thank Ms. Hisae Kawashiro, Ms. Eiko Izawa, Ms. Kenko Yoshida, and Ms. Kuniko Miki for providing assistance with data collection. None of them received financial compensation for this task.

This study was partly supported by Grants-in-Aid for Research from the National Center for Global Health and Medicine (301020) to NN and the JSPS KAKENHI (Grant Number 15K08964) 
to AY. The funders played no role in the study design, data collection and analysis, decision to publish, or preparation of the manuscript.

\section{Competing interests}

None

\section{References}

[1] Gralnek IM, Dumonceau JM, Kuipers EJ et al. Diagnosis and management of nonvariceal upper gastrointestinal hemorrhage: European Society of Gastrointestinal Endoscopy (ESGE) guideline. Endoscopy 2015; 47: a1-46

[2] Strate LL, Gralnek IM. ACG clinical guideline: Management of patients with acute lower gastrointestinal bleeding. Am J Gastroenterol 2016; 111: $459-474$

[3] Schlag C, Menzel C, Nennstiel S et al. Emergency video capsule endoscopy in patients with acute severe Gl bleeding and negative upper endoscopy results. Gastrointest Endosc 2015; 81: 889-895

[4] Green BT, Rockey DC, Portwood G et al. Urgent colonoscopy for evaluation and management of acute lower gastrointestinal hemorrhage: A randomized controlled trial. Am J Gastroenterol 2005; 100: 23952402

[5] Laine L, Shah A. Randomized trial of urgent vs. elective colonoscopy in patients hospitalized with lower GI bleeding. Am J Gastroenterol 2010; 105: 2636-2641; quiz 2642

[6] Gralnek IM, Neeman Z, Strate LL. Acute lower gastrointestinal bleeding. NEJM 2017; 376: $1054-1063$

[7] Jansen A, Harenberg S, Grenda U et al. Risk factors for colonic diverticular bleeding: A westernized community based hospital study. World J Gastroenterol 2009; 15: 457-461

[8] Strate LL, Syngal S. Timing of colonoscopy: Impact on length of hospital stay in patients with acute lower intestinal bleeding. Am J Gastroenterol 2003; 98: 317-322

[9] Smoot RL, Gostout C], Rajan E et al. Is early colonoscopy after admission for acute diverticular bleeding needed? Am J Gastroenterol 2003; 98: $1996-1999$
[10] Suzuki K, Uchiyama S, Imajyo K et al. Risk factors for colonic diverticular hemorrhage: Japanese multicenter study. Digestion 2012; 85: $261-265$

[11] Yamada A, Sugimoto T, Kondo S et al. Assessment of the risk factors for colonic diverticular hemorrhage. Dis Colon Rectum 2008; 51: $116-120$

[12] Tanaka Y, Motomura Y, Akahoshi K et al. Predictive factors for colonic diverticular rebleeding: A retrospective analysis of the clinical and colonoscopic features of 111 patients. Gut Liver 2012; 6: 334-338

[13] Pasha SF, Shergill A. ASGE Standards of Practice Committee. et al. The role of endoscopy in the patient with lower GI bleeding. Gastrointest Endosc 2014; 79: 875-885

[14] Aoki T, Nagata N, Shimbo T et al. Development and validation of a risk scoring system for severe acute lower gastrointestinal bleeding. Clin Gastroenterol Hepatol 2016; 14: 1562 -1570.e2

[15] Nagata N, Niikura R, Aoki T et al. Lower Gl bleeding risk of nonsteroidal anti-inflammatory drugs and antiplatelet drug use alone and the effect of combined therapy. Gastrointest Endosc 2014; 80: 1124 1131

[16] Nagata N, Niikura R, Yamada A et al. Acute middle gastrointestinal bleeding risk associated with NSAIDs, antithrombotic drugs, and PPIs: A multicenter case-control study. PLoS One 2016; 11: e0151332

[17] Singh A, Marshall C, Chaudhuri B et al. Timing of video capsule endoscopy relative to overt obscure GI bleeding: Implications from a retrospective study. Gastrointest Endosc 2013; 77: 761 - 766

[18] Albert J, Gobel CM, Lesske J et al. Simethicone for small bowel preparation for capsule endoscopy: A systematic, single-blinded, controlled study. Gastrointest Endosc 2004; 59: 487-491

[19] Yamada A, Watabe H, Kobayashi Y et al. Timing of capsule endoscopy influences the diagnosis and outcome in obscure-overt gastrointestinal bleeding. Hepatogastroenterology 2012; 59: 676-679

[20] Charlson M, Szatrowski TP, Peterson J et al. Validation of a combined comorbidity index. J Clin Epidemiol 1994; 47: 1245 - 1251

[21] Gerson LB, Fidler JL, Cave DR et al. ACG clinical guideline: Diagnosis and management of small bowel bleeding. Am J Gastroenterol 2015; 110: 1265 - 1287 ; quiz 1288

[22] Prakash C, Zuckerman GR. Acute small bowel bleeding: A distinct entity with significantly different economic implications compared with GI bleeding from other locations. Gastrointest Endosc 2003; 58: $330-335$ 
Supplementary Figure 1. Flow chart for management of acute-onset hematochezia after colonoscopy could not identify the definitive bleeding source.

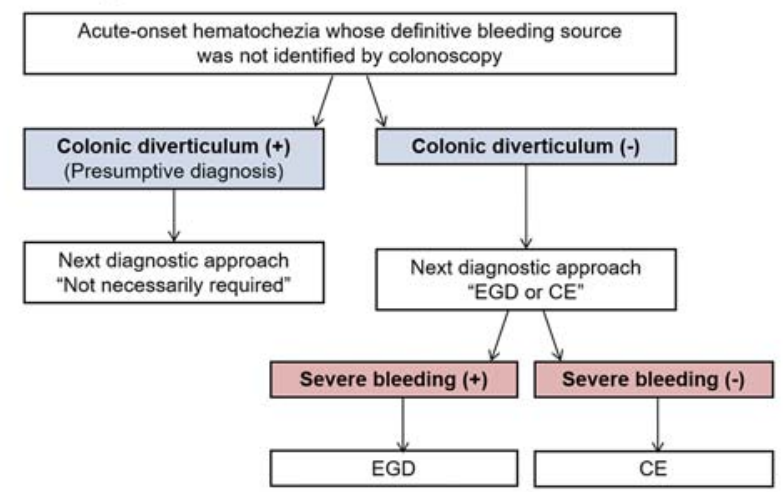

Note: The strength of the recommendation for the next diagnostic approach depends on the presence of a colonic diverticulum. The recommendation regarding the choice of the next endoscopic procedure depends on the bleeding severity.

Abbreviations: $\mathrm{CE}$, capsule endoscopy; EGD, esophagogastroduodenoscopy.

- Supplementary Fig. 1 Flow chart for management of acute-onset hematochezia when colonoscopy could not identify the definitive bleeding source. 